\title{
Pulmonary Embolism in Children: A Case Series
}

\author{
Sonam Agrawal ${ }^{1}$, Yash Shrivastava ${ }^{2}$, Rishi Bolia ${ }^{3}$, Prateek K Panda ${ }^{4}$, Indar K Sharawat ${ }^{5}$, Nowneet K Bhat ${ }^{6}$
}

\begin{abstract}
Background: Pulmonary embolism (PE) is a life-threatening event with a mortality of $\sim 10 \%$. It is relatively uncommon in children and literature regarding the condition is sparse. In adults, the classical clinical presentation is with pleuritic chest pain, hemoptysis, and dyspnea, whereas in children, the presentation is often nonspecific.

Materials and methods: Clinical features, risk factors, and outcome of children with PE presenting to our unit between December, 19 and March, 2020 were recorded.

Results: Four children [mean age: $10(6-16)$ years, 3 females], all presenting with tachycardia and dyspnea were diagnosed with PE. Different risk factors such as deep vein thrombosis, nephrotic syndrome, softtissue infection, and infective endocarditis (IE) were identified in all patients. One child died while others responded to anticoagulation.

Conclusion: We aim to highlight the importance of timely recognition of PE in children with known risk factors for the same. Early recognition and timely treatment of PE are critical to save lives.

Keywords: Children, Dyspnea, Pulmonary embolism, Tachycardia.

Indian Journal of Critical Care Medicine (2020): 10.5005/jp-journals-10071-23682
\end{abstract}

\section{INTRODUCTION}

Pulmonary embolism (PE) is a serious disease with mortality of $\sim 10 \%{ }^{1}$ ). It is an important cause of mortality in adults but is less commonly reported in children. Diagnosis of PE is often overlooked due to its low incidence and nonspecific signs and symptoms, which include dyspnea, chest pain, cough, hemoptysis, syncope, tachycardia, hypoxia, and fever. We report four cases of pediatric PE who presented to our intensive care unit (Table 1).

\section{Case Descriptions}

\section{Case 1}

A 11-year-old male presented with fever, lower limb swelling, and breathing difficulty for 5 days. On examination, he was febrile, with tachycardia and tachypnea. Chest X-ray revealed bilateral in-hemogeneous nodular opacities with cavitatory consolidation. Venous Doppler showed right popliteal vein thrombosis. Computed tomography pulmonary angiography (CTPA) revealed septic PE. Child was treated with intravenous antibiotics and subcutaneous low-molecular weight heparin (LMWH) and other supportive care. However, after 2 days of intensive care stay, the child died due to massive acute pulmonary hemorrhage.

\section{Case 2}

A 6-year-old girl, a known case of nephrotic syndrome (NS) presented with breathlessness, anasarca, and decreased urine output for 7 days. On examination she had tachycardia. Her electrocardiogram (ECG) showed sinus tachycardia with ST segment elevation and T wave changes (Fig. 1A). After an echocardiogram raised suspicion of $P E$, a CTPA was performed which showed acute PE (Fig. 1B) for which anticoagulation was started with LMWH and later switched over to warfarin.

\section{Case 3}

A 7-year-old girl presented with abdominal pain in right iliac fossa, fever, and dyspnea for 5 days. On examination, she had
${ }^{1-6}$ Department of Paediatrics, All India Institute of Medical Sciences Rishikesh, Uttarakhand, India

Corresponding Author: Yash Shrivastava, Department of Paediatrics, All India Institute of Medical Sciences Rishikesh, Uttarakhand, India, Phone: +91 9717295788, e-mail: dr.yash.24@gmail.com

How to cite this article: Agrawal S, Shrivastava Y, Bolia R, Panda PK, Sharawat IK, Bhat NK. Pulmonary Embolism in Children: A Case Series. Indian J Crit Care Med 2020;24(12):1272-1275.

Source of support: Nil

Conflict of interest: None

pallor, tachypnea, tachycardia, and tenderness in right iliac fossa. Laboratory analysis showed leukocytosis, raised erythrocyte sedimentation rate and C-reactive protein. Chest X-ray showed heterogeneous opacities in the left lower segment. CT scan revealed an iliopsoas abscess and right iliosacral osteomyelitis. During the hospital stay, she developed right lower limb tenderness and venous Doppler showed right popliteal vein thrombosis. CTPA showed PE. She was treated with antibiotics, LMWH, and surgical exploration with evacuation of pus.

\section{Case 4}

A 16-year-old female presented with fever, cough, and dyspnea for 20 days. On examination she had tachycardia and a continuous murmur best heard in the left second intercostal space. Chest X-ray showed multiple cavitatory lesions in the right lung with right-sided hydropneumothorax (Fig. 2). Echocardiography showed a large patent ductus arteriosus (PDA). CTPA was suggestive of septic emboli. Child was treated with IV antibiotics, LMWH, and intercostal drain for hydropneumothorax.

\section{Discussion}

The PE in the pediatric population is less common when compared with adults though exact incidence is not known, as many cases 
Table 1: Clinical features, salient investigations and outcome of children with pulmonary embolism

\begin{tabular}{|c|c|c|c|c|}
\hline & Patient 1 & Patient 2 & Patient 3 & Patient 4 \\
\hline Age & 11 years & 6 years & 7 years & 16 years \\
\hline Sex & Male & Female & Female & Female \\
\hline Weight (kg) & 28 & 30 & 28 & 44.5 \\
\hline Height $(\mathrm{cm})$ & 120 & 112 & 113 & 155 \\
\hline BMI $\left(\mathrm{kg} / \mathrm{m}^{2}\right)$ & 15 & 24 & 22 & 19.7 \\
\hline \multirow[t]{3}{*}{ Presentation } & Fever & Seizure & Abdomen pain Fever & Fever \\
\hline & Lower limb swelling & Hypotension & & Cough \\
\hline & Respiratory distress & & & Difficulty in breathing \\
\hline $\begin{array}{l}\text { Risk factor for } \\
\text { pulmonary } \\
\text { embolism }\end{array}$ & Right popliteal vein thrombosis & Nephrotic syndrome & $\begin{array}{l}\text { Right hip osteomy- } \\
\text { elitis with right psoas } \\
\text { abscess with septic } \\
\text { thrombophlebitis }\end{array}$ & $\begin{array}{l}\text { Infective endocarditis } \\
\text { MRSA }\end{array}$ \\
\hline \multicolumn{5}{|l|}{ Vitals } \\
\hline Heart rate & $136 /$ minutes & $150 /$ minutes & $142 /$ minutes & $126 /$ minutes \\
\hline Respiratory rate & $36 /$ minutes & $28 /$ minutes & $28 /$ minutes & $22 /$ minutes \\
\hline $\mathrm{SpO}_{2}$ & $90 \%$ & $97 \%$ & $95 \%$ & $96 \%$ \\
\hline Blood pressure & $100 / 60 \mathrm{~mm} \mathrm{Hg}$ & $106 / 72 \mathrm{~mm} \mathrm{Hg}$ & $110 / 66 \mathrm{~mm} \mathrm{Hg}$ & $110 / 60 \mathrm{~mm} \mathrm{Hg}$ \\
\hline \multicolumn{5}{|l|}{ Investigation } \\
\hline D-dimer & $5.5 \mathrm{mg} / \mathrm{L}$ & & & \\
\hline \multirow[t]{2}{*}{ ECG } & Sinus tachycardia & Sinus tachycardia & Sinus tachycardia & Sinus tachycardia \\
\hline & & ST-segment elevation & & \\
\hline \multirow[t]{2}{*}{ Echocardiography } & $\begin{array}{l}\text { Dilated RA and RV } \\
\text { RV dysfunction } \\
\text { Moderate TR }\end{array}$ & $\begin{array}{l}\text { Dilated RA and RV } \\
\text { Mild TR }\end{array}$ & Dilated RV with mild PAH & $\begin{array}{l}\text { ACCHD, } 10 \text { mm large } \\
\text { PDA, Left to right shunt } \\
>2: 1 .\end{array}$ \\
\hline & Severe $\mathrm{PAH}$ & & & $\begin{array}{l}\text { Dilated LA and LV. Mod- } \\
\text { erate TR. Severe PAH }\end{array}$ \\
\hline $\begin{array}{l}\text { Venous Doppler } \\
\text { of lower limbs }\end{array}$ & Right popliteal vein thrombosis & Normal & $\begin{array}{l}\text { Right popliteal vein throm- } \\
\text { bosis }\end{array}$ & Normal \\
\hline $\begin{array}{l}\text { CT-pulmonary } \\
\text { angiography }\end{array}$ & $\begin{array}{l}\text { Random peripheral predominant } \\
\text { nodules and cavitatory } \\
\text { consolidation in bilateral lung } \\
\text { parenchyma (feeding vessel sign } \\
\text { seen) with mild bilateral pleural } \\
\text { effusion-septic emboli }\end{array}$ & $\begin{array}{l}\text { Acute thrombus in posterior } \\
\text { basal segmental branch (3rd } \\
\text { order) of the right descending } \\
\text { pulmonary artery }\end{array}$ & $\begin{array}{l}\text { Pulmonary thromboembo- } \\
\text { lism involving segmental } \\
\text { branches of left lower } \\
\text { lobe pulmonary artery } \\
\text { with possible segmental } \\
\text { pulmonary infarct in left } \\
\text { basal segments of left } \\
\text { lower lobe }\end{array}$ & $\begin{array}{l}\text { Thick-walled cavities in } \\
\text { B/L lung parenchyma } \\
\text { with air fluid levels? } \\
\text { Septic emboli with } \\
\text { large PDA (10 mm) with } \\
\text { dilated MPA, RPA, LPA, } \\
\text { LA, and Left ventricle }\end{array}$ \\
\hline Outcome & Died & Discharged and in follow-up & $\begin{array}{l}\text { Discharged and in } \\
\text { follow-up }\end{array}$ & $\begin{array}{l}\text { Discharged and in } \\
\text { follow-up PDA closure } \\
\text { planned }\end{array}$ \\
\hline
\end{tabular}

RA, right atrium; RV, right ventricle; $L A$, left atrium; LV, left ventricle; $P D A$, patent ductus arteriosus; MPA, main pulmonary artery; RPA, right pulmonary artery; LPA, left pulmonary artery; PAH, pulmonary arterial hypertension

remain unrecognized. In an autopsy series, Buck et al. $^{2}$ reported that $\sim 50 \%$ of children with PE had signs and symptoms of PE in the ante-mortem period and the diagnosis was considered only in a third of them. Studies have shown an incidence of PE of 0.3 to 1.4 per 10,000 children per year, ${ }^{1,3}$ which is increasing in recent years. Carpenter et al. $^{4}$ reported a $200 \%$ increase in PE in hospitalized children in the United States, increasing from 9.8 to 24.7 per 10,000 over a period of 14 years. PE has a bimodal age of presentation and is more common in neonates and adolescents. ${ }^{1,3,5}$

Neonates have high risk of PE due to indwelling central venous catheter, $^{3}$ while obesity ${ }^{3}$ and oral contraceptives ${ }^{1,3,5}$ are the most common risk factor in adolescents. Deep vein thrombosis (DVT) and hypercoagulable states are other important risk factors. ${ }^{6}$ We identified risk factors for PE in all children in the current series.
Case 1 had DVT as a risk factor, which is an important risk factor for PE in adults but is uncommon in children. The incidence of DVT is 5 to 14 per 10,000 pediatric hospital admission per year in various studies. ${ }^{6-8}$ Possibility of a thrombophilic state was considered; however, workup could not be done as it was deferred initially due to the acute presentation and the child died subsequently.

Case 2 had NS which is an important risk factor for PE. ${ }^{5,9,10}$ In NS, abnormality in coagulation cascade predisposes to venous thromboembolism and PE. ${ }^{10,11}$

Case 3 had osteomyelitis of the right hip and a psoas abscess, which lead to septic PE. Septic PE is less common in children. Softtissue abscess and osteomyelitis are common causes of septic PE. ${ }^{12}$

Case 4 had PDA with infective endocarditis (IE), hydropneumothorax requiring inter-costal drainage and methicillin- 

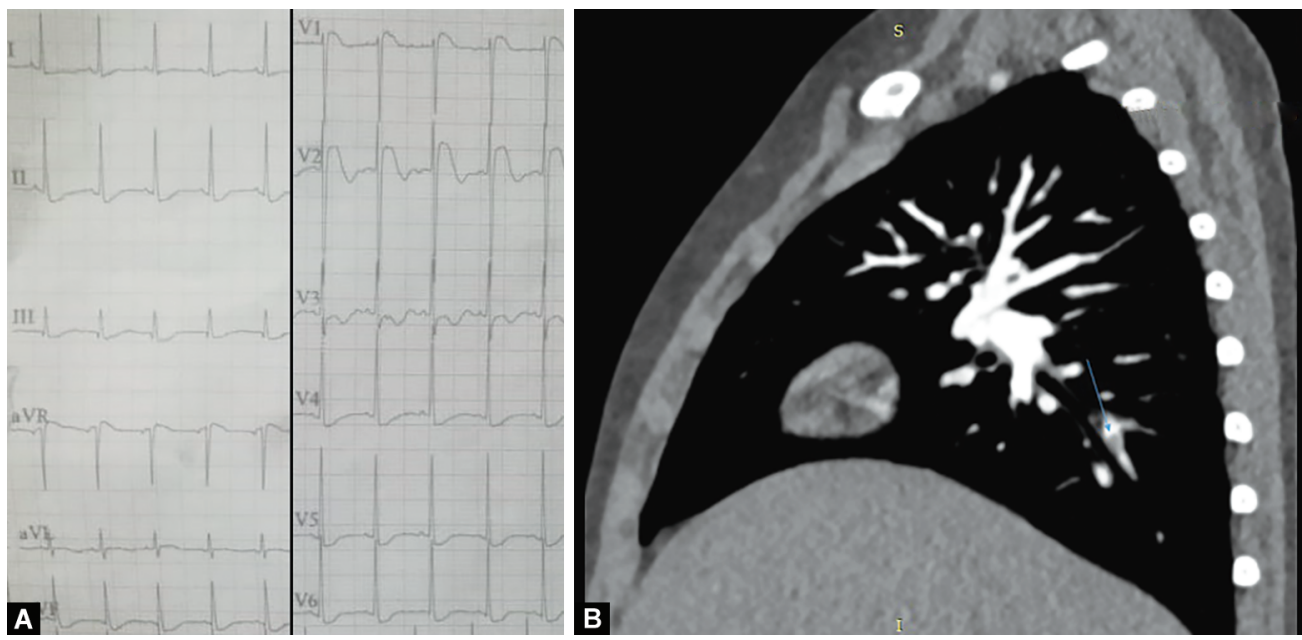

Figs 1A and B: (A) 12-lead ECG showing sinus tachycardia and ST-segment elevation in lead V1-V2; (B) CT pulmonary angiography showing nonenhancing thrombus in posterior basal branch of right posterior descending artery

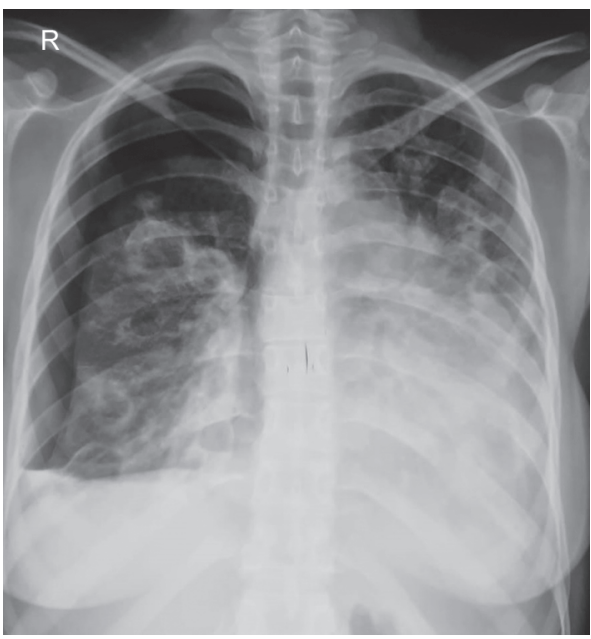

Fig. 2: Chest $X$-ray showing multiple cavitatory lesions in right lung with right-sided hydropneumothorax

resistant Staphylococcus aureus infection. Wong et al. ${ }^{12}$ found that S. aureus was the causative organism in 9 out of 10 cases, 8 of which were methicillin resistant. In this series, three patients had pneumothorax like our case.

The ECG in PE shows sinus tachycardia, $\mathrm{S}_{1} \mathrm{Q}_{3} \mathrm{~T}_{3}$ pattern and ST segment changes. ${ }^{1,5}$ All our cases had sinus tachycardia, and case 2 had ST segment elevation in lead V1-V2. Chest X-ray in case of septic emboli shows multiple peripherally located areas of nodularity and cavitation, as seen in cases 1 and 4 . D-dimer is sensitive but not specific for PE, it is not validated for use in children., Echocardiography shows right ventricular dilation and dysfunction, and pulmonary hypertension. Venous Doppler ultrasound is useful to diagnose DVT. CTPA ${ }^{1,5}$ is the diagnostic test of choice and has advantage of being widely available. Pulmonary angiography is the gold standard ${ }^{1}$ but is invasive and not routinely performed. Venous Doppler ultrasound, echocardiography, and CTPA were performed in all cases (Table 1).

All four cases had tachycardia and dyspnea at presentation, which was attributed to other causes initially leading to a diagnostic delay of approximately 24 hours. On retrospectively looking into the cause of delay, it was noticed that PE was not kept in the initial differential diagnosis due to nonspecific clinical features as a presenting complaint and the relative rarity of $\mathrm{PE}$ in children even though a risk factor was present in all. Pointers which lead us to diagnosis of PE are as follows: case 1 venous Doppler showed DVT and D-dimer was raised, case 2 ECG and echocardiographic findings raised possibility of $\mathrm{PE}$, case $3 \mathrm{CT}$ abdomen showed right iliopsoas abscess and venous Doppler right popliteal vein thrombosis, and in case 4, PDA with IE and worsening of respiratory status. Cases 1 and 2 had submassive PE and cases 3 and 4 had low risk PE according to American Heart Association (AHA) guidelines. ${ }^{13}$

Management involves anticoagulation after hemodynamic stabilization. LMWH is given in acute phase and switched over to warfarin after 5-10 days. Duration of anticoagulation ${ }^{5}$ for first episode of venous thromboembolism is 3-6 months, long-term for patients with chronic risk factors and lifelong for patients with of congenital thrombophilic disorders. Most children recover uneventfully with mortality $\sim 10 \%$ in children. All our children were treated with LMWH for 5-7 days and are now on warfarin for 6 months. One child died due to pulmonary hemorrhage and other three improved with anticoagulation.

\section{Conclusion}

The $P E$ is rare in children and a high index of suspicion is required to diagnose it in patients with risk factors. ECG and echocardiography help to suspect PE and CTPA is important to confirm the diagnosis. Early recognition and timely treatment of $\mathrm{PE}$ is critical to save lives.

\section{ACKnowledgment}

The authors thank Dr Aakriti Kapoor for providing the images of cases.

\section{References}

1. Dijk FN, Curtin J, Lord D, Fitzgerald DA. Pulmonary embolism in children. Paediatr Respir Rev 2012;13(2):112-122. DOI: 10.1016/j. prrv.2011.09.002.

2. BuckJR, Connors RH, Coon WW, Weintraub WH, Wesley JR, Coran AG. Pulmonary embolism in children. J Pediatr Surg 1981;16(3):385-391. DOI: 10.1016/s0022-3468(81)80700-2.

3. Marcì M, Castiglione MC, Sanfilippo N. Pulmonary embolism in children: a report of two cases. J Cardiol Curr Res 2016;5(3):00166. DOI: 10.15406/jccr.2016.05.00166. 
4. Carpenter SL, Richardson T, Hall M. Increasing rate of pulmonary embolism diagnosed in hospitalized children in the United States from 2001 to 2014. Blood Adv 2018;2(12):1403-1408. DOI: 10.1182/ bloodadvances.2017013292.

5. Navanandan N, Stein J, Mistry RD. Pulmonary embolism in children. Pediatr Emerg Care 2019;35(2):143-151. DOI: 10.1097/ PEC.0000000000001730.

6. Stein PD, Kayali F, Olson RE. Incidence of venous thromboembolism in infants and children: data from the national hospital discharge survey. J Pediatr 2004;145(4):563-565. DOI: 10.1016/j.jpeds.2004. 06.021 .

7. Audu CO, Wakefield TW, Coleman DM. Pediatric deep venous thrombosis. J Vasc Surg Venous Lymphat Disord 2019;7(3):452-462. DOI: 10.1016/j.jvsv.2018.12.012.

8. Nair A, Kamtikar S. A brief review of deep vein thrombosis in pediatric patients. Indian J Vasc Endovasc Surg 2015;2(3):101. DOI: 10.4103/0972-0820.166935.

9. Song Z, Wu H, Cao H, Tang M, Yang S, Qin L. Nephrotic syndrome with acute pulmonary embolism in young adults: two case reports. Medicine (Baltimore) 2018;97(29):e11495. DOI: 10.1097/ MD.0000000000011495.

10. Citak A, Emre S, Sâirin A, Bilge I, Nayir A. Hemostatic problems and thromboembolic complications in nephrotic children. Pediatr Nephrol 2000;14(2):138-142. DOI: 10.1007/ s004670050029.

11. Kinane TB, Grabowski EF, Sharma A, Nimkin K, King ME, Cornell LD. Case records of the Massachusetts general hospital. Case 7-2008. A 17-year-old girl with chest pain and hemoptysis. N Engl J Med 2008;358(9):941-952. DOI: 10.1056/NEJMcpc0708507.

12. Wong KS, Lin TY, Huang YC, Hsia SH, Yang PH, Chu SM. Clinical and radiographic spectrum of septic pulmonary embolism. Arch Dis Child 2002;87(4):312-315. DOI: 10.1136/adc.87.4.312.

13. Jaff MR, McMurtry MS, Archer SL, Cushman M, Goldenberg N, Goldhaber SZ, et al. Management of massive and submassive pulmonary embolism, iliofemoral deep vein thrombosis, and chronic thromboembolic pulmonary hypertension: a scientific statement from the American Heart Association. Circulation 2011;123(16):17881830. DOI: 10.1161/CIR.0b013e318214914f. 